\title{
O SISTEMA DE DOBRAMENTO APIAÍ, ESTADO DO PARANÁ'
}

\author{
ALBERTO P. FIORI**
}

\begin{abstract}
THE APIAÍ FÕLD SYSTEM, PARANÁ STATE, BRAZIL. Folds belonging to this system are younger than the thrusting episodes that affected the Açungui Group, as indicated by the fact that they are outlined by $\mathrm{S}$, foliation (which, in turn, is paralell to S,), as well as by the thrust faults, both strutures develloped through the first deformative event. The folds show different styles, including some with conical geometry. Axial plane foliation is a noticeable develloped feature but it is not penetrative all over the area; fold axis have a remarkable NE-S W direction and the axial planes are generally subvertical. These features are easily recognized in S, pole stereograms because they draw partial or full guirlands. Major folds were mapped and discussed in more detail. It is postulated here that this fold system could be an answer to second order compressive stress, oriented from NW to SE, associated to clockwise displacement along the main strike-slip faults in this area, with exception of the Setuva Antiform which cautiousness may be associated to a anti-clockwise (left-lateral) reactivation of the Lancinha strike-slip fault
\end{abstract}

Keywords: Fold system, cylindrical folds, conical folds, stereograms, faults reactivation.

\begin{abstract}
RESUMO As dobras do sistema de Dobramento Apiaí são posteriores ao evento de cavalgamento que atingiu o Grupo Açungui, pois são desenhadas pela foliação S, (paralela a S,) e pelas falhas de cavalgamento, ambas originadas durante esse primeiro evento deformacional. Apresentam estilo bastante variado, algumas inclusive com geometria cênica. Há desenvolvimento de foliação em posição planoaxial, porém, esta não é penetrativa por toda a área; o eixo tem direção NE-SW e a superfície axial é geralmente subvertical. São facilmente reconhecidas em estereogramas de pólos de S, ao delinearem guirlandas parciais ou completas. Algumas maiores foram cartografadas e analisadas com mais detalhes. É possível que este sistema de dobramento esteja geneticamente ligado ao esforço compressivo de segunda ordem, de direção NW-SE, associado à movimentação lateral dextral das principais transcorrências paranaenses, com exceção da Antiforma do Setuva, que duvidosamente pode estar relacionada a uma reativação anti-horária da Falha da Lancinha.
\end{abstract}

Palavras-chave: Sistema de dobramento, dobras cilíndricas, dobras cônkas, estereogramas, reativação de falhas.

INTRODUÇÃO A evolução estrutural do Grupo Açungui é bastante complexa, resultado da superposição de três eventos principais de deformação. O mais antigo está relacionado a uma tectônica de cavalgamento, que causou generalizada aloctonia do grupo e gerou uma série de estruturas geneticamente associadas, como falhas de cavalgamento, dobras-falha $D_{1}$, foliações $S$, (paralela a $\left.S^{\prime \prime}\right), S$ e $S_{2}$, e lineações dos tipos a e b que, no conjunto, constituem $\mathrm{p}$ chamado Sistema de Cavalgamento Açungui (SCA) (Fiori et al. 1987, Fiori 1991, 1992a).

As principais falhas de cavalgamento cortaram a coluna estratigráfica original em fatias e, após transportá-las à distância, empilharam-nas uma sobre as outras segundo o modelo de duplex (Boyer 1986, Boyer \& Elliott 1982, Butler 1982), originando uma nova e aparente sucessão estratigráfica. A atual organização estratigráfica do Grupo Açungui é o resultado final desse empilhamento de fatias ou lascas tectônicas, cada uma contendo internamente uma parte preservada da coluna original.

Os pacotes litológicos com sucessão estratigráfica regular, recuperados dentro das diversas fatias tectônicas mapeadas, foram denominados de conjuntos litológicos por Fiori (1992b), tendo ao todo reconhecido nove dentro do Grupo Açungui na área enfocada. Os Conjuntos Juruqui, Rio Branco e Morro Grande compõem a Formação Capiru e estão separados por falhas de cavalgamento; os Conjuntos Bromado, Coloninha e Saivá compõem a Formação Votuverava, com os dois primeiros separados por falha de cavalgamento, enquanto os Conjuntos Tacaniça, Capivara e Viituruvu compõem a Formação Antinha. Nesta última, a organização estratigráfica original parece estar preservada, nã̃o tendo sido reconhecidos contatos tectônicos entre os conjuntos, porém, a formação como um todo é aloctone ou parautoctone, pois seu limite inferior é tectônico, representado pela Falha do Brejal (Fiori 1991).

$\mathrm{O}$ segundo evento deformacional que atingiu o Grupo Açungui refere-se a um dobramento generalizado das estruturas anteriormente formadas, podendo ser verificado no afloramento ou na escala de mapas. As estruturas geradas nessa oportunidade constituem o Sistema de Dobramento Apiaí (SDA) (Fiori et al. 1987, Fiori 1991) e seu estudo detalhado é o objeto principal deste trabalho.

$\mathrm{O}$ terceiro evento deformacional refere-se a uma tectônica transcorrente, à qual estão relacionados os principais lineamentos da área. Como conseqüência, os empilhamentos tectônicos anteriormente formados, foram truncados e deslocados, justapondo-se conjuntos litológicos distintos e originalmente situados a grandes distâncias. As estruturas desse evento constituem o Sistema de Transcorrência Lancinha, sendo as falhas da Lancinha e de Morro Agudo seus principais componentes. Subdividem a área em três blocos tectônicos e foram denominados de $\mathbf{C}$ (ou Cerro Azul), D (ou Tunas) e E (ou Bocaiúva do Sul) de noroeste para sudeste, por Fiori (1984) e Fiori et al (1987). No bloco C, aparece a Formação Antinha; no D, a Formação Votuverava e, no E, a Formação Capiru.

AS DOBRAS D $\mathbf{2}$ DO SDA O Sistema de Dobramento Apiaí é caracterizado pelo dobramento do acamamento reliquiar $\mathrm{S}_{0}$, paralelamente ao qual aparece a foliação $\mathrm{S}_{1}$, esta última gerada durante o evento de cavalgamento. As dobras podem ser identificadas em afloramento, em amostra de mão, em mapas e em diagramas estruturais de pólos de $\mathrm{S}_{1}$ e/ou $\mathrm{S}_{0}$. São de dimensões muito variadas, diversificando em perfil 


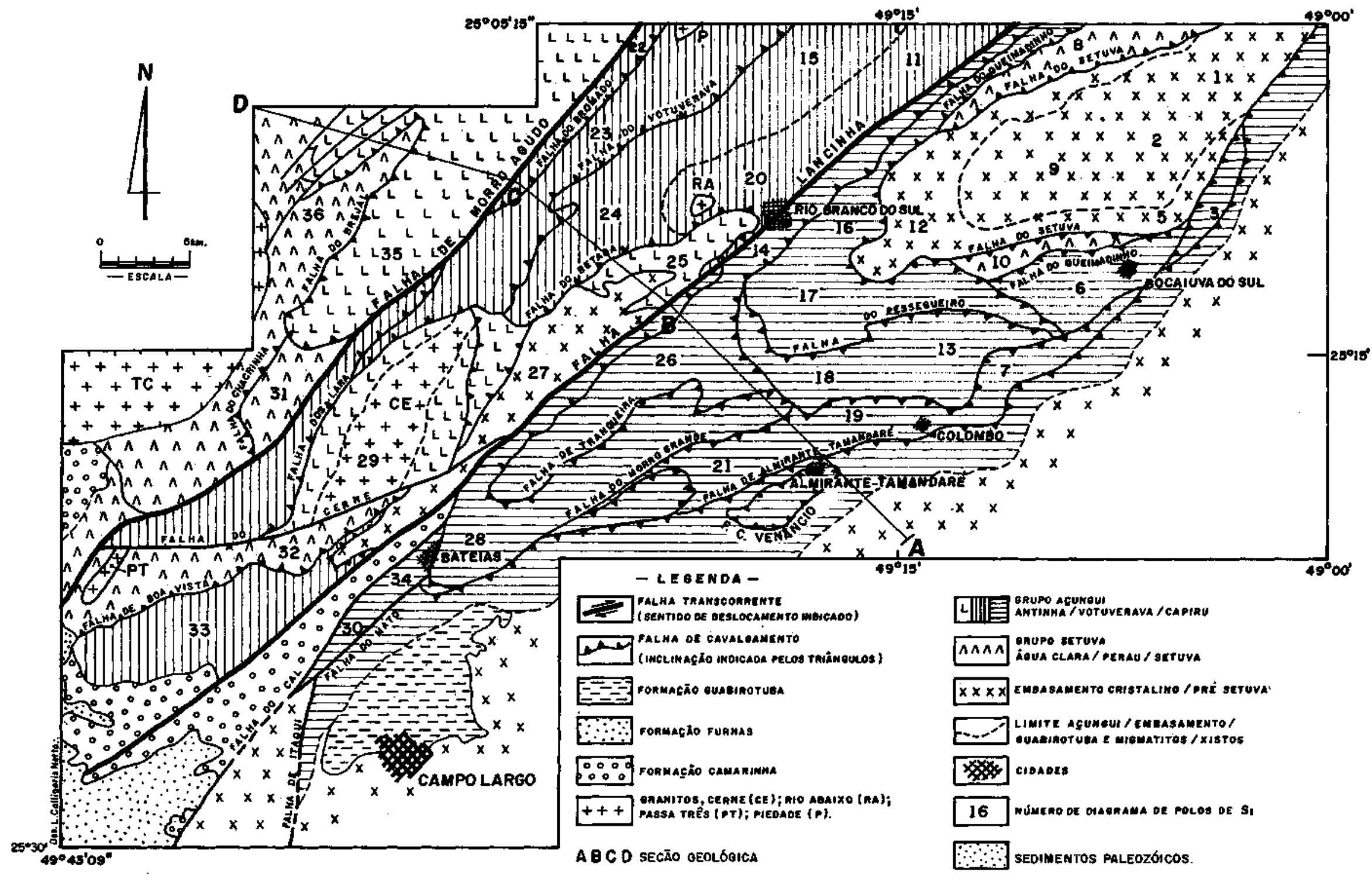

Figura 1 - Mapa estrutural da área estudada, mostrando os traços das maiores falhas e dobras cartografadas. Os números indicam a localização dos estereogramas de pólos de $S_{r}$. As letras ABCD indicam a trajetória da seção geológica, representada na figura 9

Figure 1 - Structural map of the studied area, showing major regional fault traces (thrust and transcurrent faults). Numbers indicate geographic localization of equal-area stereographic projection for $\mathrm{S}$, poles. ABCD letters indicate structural section trajetory (see Fig. 9) 


\begin{tabular}{|c|c|c|c|c|c|c|c|}
\hline $\begin{array}{l}\frac{\alpha}{2} \\
\frac{\alpha}{\delta} \\
\frac{\alpha}{0}\end{array}$ & $\begin{array}{l}\vec{n} \\
山 \\
0 \\
0 \\
0 \\
\partial \\
0 \\
0 \\
\alpha\end{array}$ & $\mid \begin{array}{c}\text { ISOCURVAS } \\
\%\end{array}$ & $\begin{array}{c}\text { ATITUDES } \\
\text { DE } \beta\end{array}$ & $\frac{\frac{\alpha}{8}}{\frac{8}{\delta}}$ & 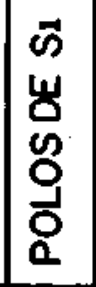 & $\begin{array}{c}\text { ISOCURVAS } \\
\%\end{array}$ & $\begin{array}{c}\text { ATITUDES } \\
\text { DE } \beta\end{array}$ \\
\hline 01 & 63 & $\begin{array}{l}1.6-3.2-4.6- \\
6.3-7.9-9.5\end{array}$ & $\begin{array}{l}\text { N74 E / 10 } \\
\text { S8OW/10 }\end{array}$ & 19 & 186 & $\begin{array}{l}0.2-1.0-1.6-2.6 \\
3.4-4.2-5.0\end{array}$ & $565 w / 15$ \\
\hline 02 & 49 & $\begin{array}{l}2-4-6-8- \\
10=12-14\end{array}$ & $\$ 38 w / 10$ & 20 & 39 & $\begin{array}{l}1.3-3.5-5.7- \\
7.2\end{array}$ & NSBE / 28 \\
\hline 03 & 99 & $1-3-5-7$ & $544 w / 15$ & 21 & 81 & $\begin{array}{l}0.6-2.3-4.0- \\
5.4-7.2\end{array}$ & $s 84 W / 05$ \\
\hline 04 & 46 & $2.2-4.3-6.5-9.7$ & $\begin{array}{l}N 62 W / 10 \\
s 63 w / 10\end{array}$ & 22 & 37 & $3-6-9-12-15$ & N $48 \mathrm{E} / 05$ \\
\hline 06 & 58 & $1.7-5.2-10.3$ & $N 84 W / 08$ & 23 & 69 & $1.4-2.8-5.7-8.6$ & N38E/30 \\
\hline 106 & 35 & $2-6-10-14$ & $S 58 w / 26$ & 24 & 40 & \begin{tabular}{|l|}
$2.5-5-7.5-10.0-$ \\
12.5 \\
\end{tabular} & N45E / 40 \\
\hline 07 & 131 & $2-4-6-8-10-12$ & s $60 w / 15$ & 25 & 31 & $3-6-9-12-15$ & $\begin{array}{l}N 32 E / 50 \\
564 W / 25\end{array}$ \\
\hline 08 & 58 & \begin{tabular}{|l|}
$1.7-3.4-5.2-8.6-$ \\
$12-15.5-19.0$
\end{tabular} & \begin{tabular}{|l|} 
N 76 E $/ O$ \\
S $76 W / 0$ \\
\end{tabular} & 26 & 98 & $\begin{array}{l}0.5-1.7-2.9 \\
4.1-6.3-7.5 \\
\end{array}$ & $562 W / 20$ \\
\hline 09 & 40 & $4-12-20-28$ & NBBE/OB & 27 & 53 & $2-4-6-8-10$ & N42E/OB \\
\hline 10 & 30 & $3-6-9-12$ & NBOW/10 & 28 & 82 & $1-2-4-6-8-10$ & NG6E / IO \\
\hline 11 & 34 & $4-9-13-17-22$ & $S 48 w / 20$ & 29 & 122 & $\begin{array}{l}1.5-3.0-4.5- \\
6.0-7.5\end{array}$ & $\begin{array}{l}\text { N59E } / 50 \\
S 42 W / 60 \\
\end{array}$ \\
\hline 12 & 39 & $2-4-6-\theta$ & $S 65 w / 20$ & 30 & 75 & \begin{tabular}{|l|}
$1.3-2.6-4.0-5.3-$ \\
$6.7-8.0-9.3$
\end{tabular} & $\begin{array}{l}N 46 E / 10 \\
S 45 W / 10\end{array}$ \\
\hline 13 & 551 & $\begin{array}{l}1.5-3.0-4.5-6.0 \\
7.5-9.0-10.5-12.5 \\
\end{array}$ & $589 w / 20$ & 31 & 94 & $2-3-4-5$ & $\begin{array}{l}\text { N19E/07 } \\
S 21 W / 10 \\
\end{array}$ \\
\hline 14 & 25 & $3-6-9-12-14$ & $558 W / 20$ & 32 & 35 & $3-6-9-12-15-18$ & N63E /40 \\
\hline 15 & 42 & $5-10-15-20$ & $\begin{array}{l}N 44 E / 12 \\
S 44 W / 16\end{array}$ & 33 & 159 & $1-2-3-4-5$ & $54 l w / 60$ \\
\hline 16 & 90 & \begin{tabular}{|l|}
$1.1-2.2-4.4-6.6$ \\
$7.7-8.9-10-11.1$ \\
\end{tabular} & S35 W/10 & 34 & 113 & $2-4-6-8-10-12$ & $s 45 w / 36$ \\
\hline 17 & 46 & $\begin{array}{l}2.2-4.3-6.5= \\
6.7-10.8-13 \\
\end{array}$ & $\$ 78 w / 08$ & 35 & 196 & $\begin{array}{r}1-3-5-7-9 \\
*\left(\text { Polos de } S_{0}\right) \\
\end{array}$ & N 52 E / 10 \\
\hline 18 & 113 & $\begin{array}{l}1.8-3.6-5.4- \\
7.2-9.0\end{array}$ & S5ow/40 & 36 & 29 & $1-4-7-11$ & N47E/10 \\
\hline
\end{tabular}

Quadro 1 - Resumo dos dados dos estereogramas apresentados na figura 2

Chart 1 - Summary of equal-area projections data, presented in figure 2

desde abertas a cerradas ou isoclinais. Seus eixos são geralmente suborizontais, direcionados para nordeste-sudoeste, e com planos axiais inclinados a ângulos maiores que $45^{\circ}$.

Em muitos casos, pode-se observar a presença de foliação planoaxial nessas dobras, enquanto, em outros, parece não existir, e foi designada de $\mathrm{S}_{3}$ (Fiori 1991), não estando entretanto bem desenvolvida pela área. É reconhecido com mais facilidade em litologias de granulometria bem fina, a exemplo de filitos e ritmitos, podendo ser distinguida das foliações $\mathrm{S}$, e $\mathrm{S}_{2}$ - estas duas relacionadas aos cavalgamentos (Fiori 1992c), pelo seu aspecto homogêneo (não é de fatiamento) e por não apresentar deslocamentos visíveis ao longo de seus planos. 

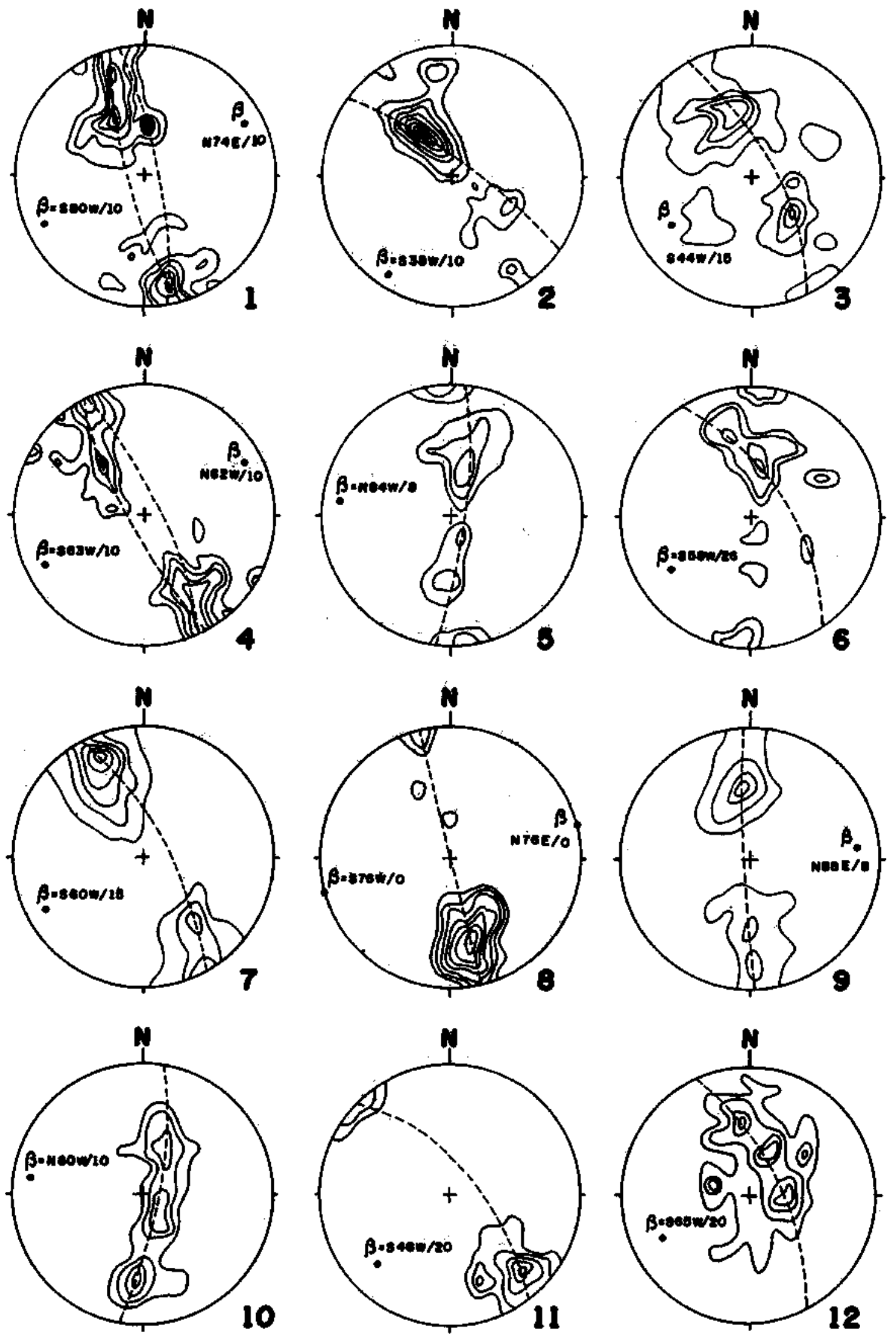

Figura 2 - Estereogramas de pólos de $S_{1}$ das diversas subáreas. Projeção no hemisfério inferior. A localização de cada estereograma está apresentada na figura 1. As curvas de isoporcentagens foram traçadas em um diagrama de igual área, com projeção no hemisfério inferior. As atitudes dos eixos $\beta$ estão indicadas no próprio diagrama

Figure 2 - Stereonets of $S_{1}$ poles, from different sites of studied area, indicated by numbers in figure 1. Data are contoured in equal-area, lower hemisphere projection. $\beta$ axis atitudes are indicated 

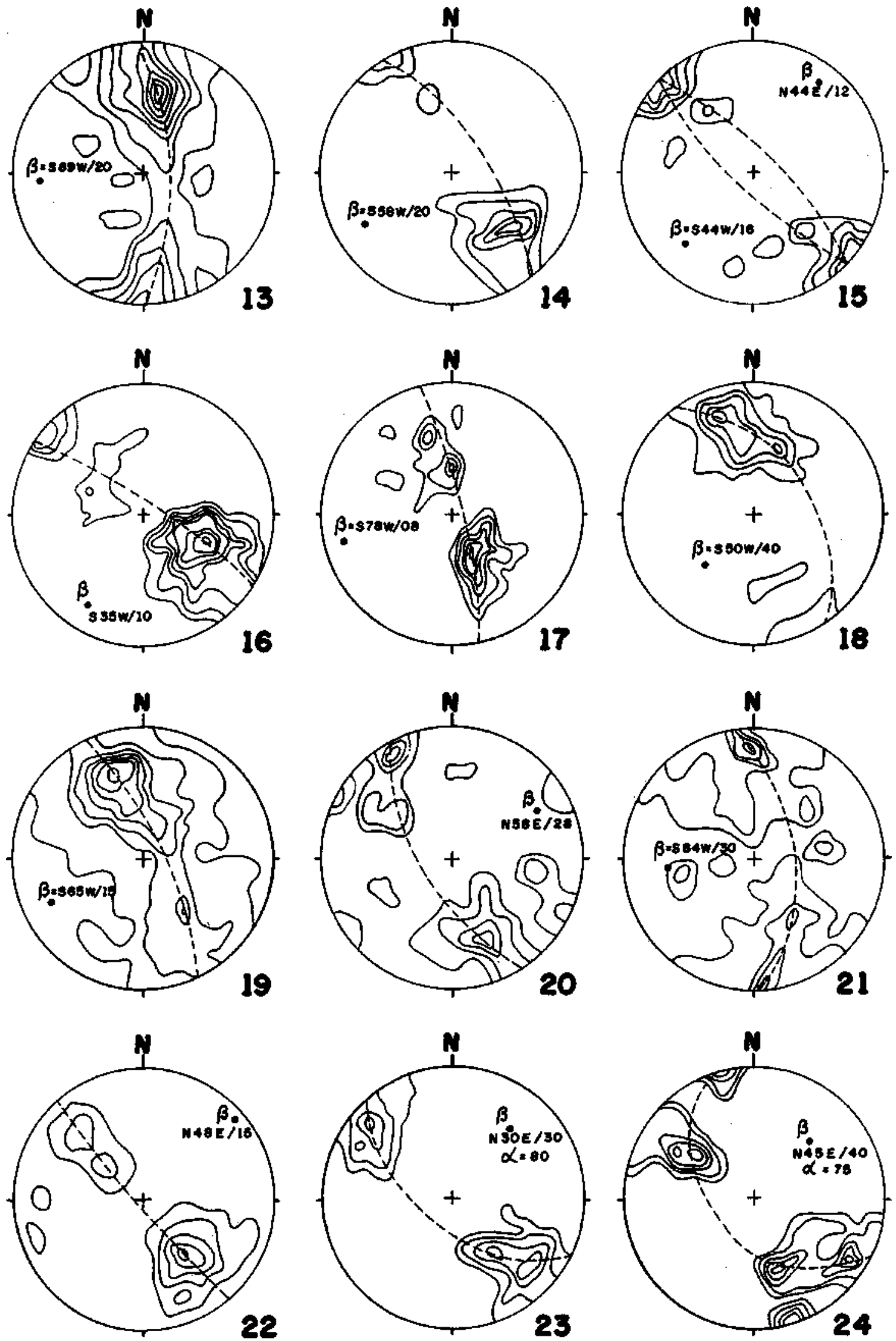

Figura 2 - Continuação

Nos diagramas estruturais, os pólos da foliação $\mathrm{S}_{1}$ mostram distribuições em guirlandas parciais ou completas, havendo casos de distribuição cônica e de predomínio de um flanco sobre o outro, o que pode, nesse caso, indicar uma certa assimetria. Os eixos estatísticos tem direção nordestesudoeste, com maior recorrência de caimentos para o quadrante sudoeste na Formação Capiru, e para nordeste, nas Formações Votuverava e Antinha. Grandes dobras, delineadas 

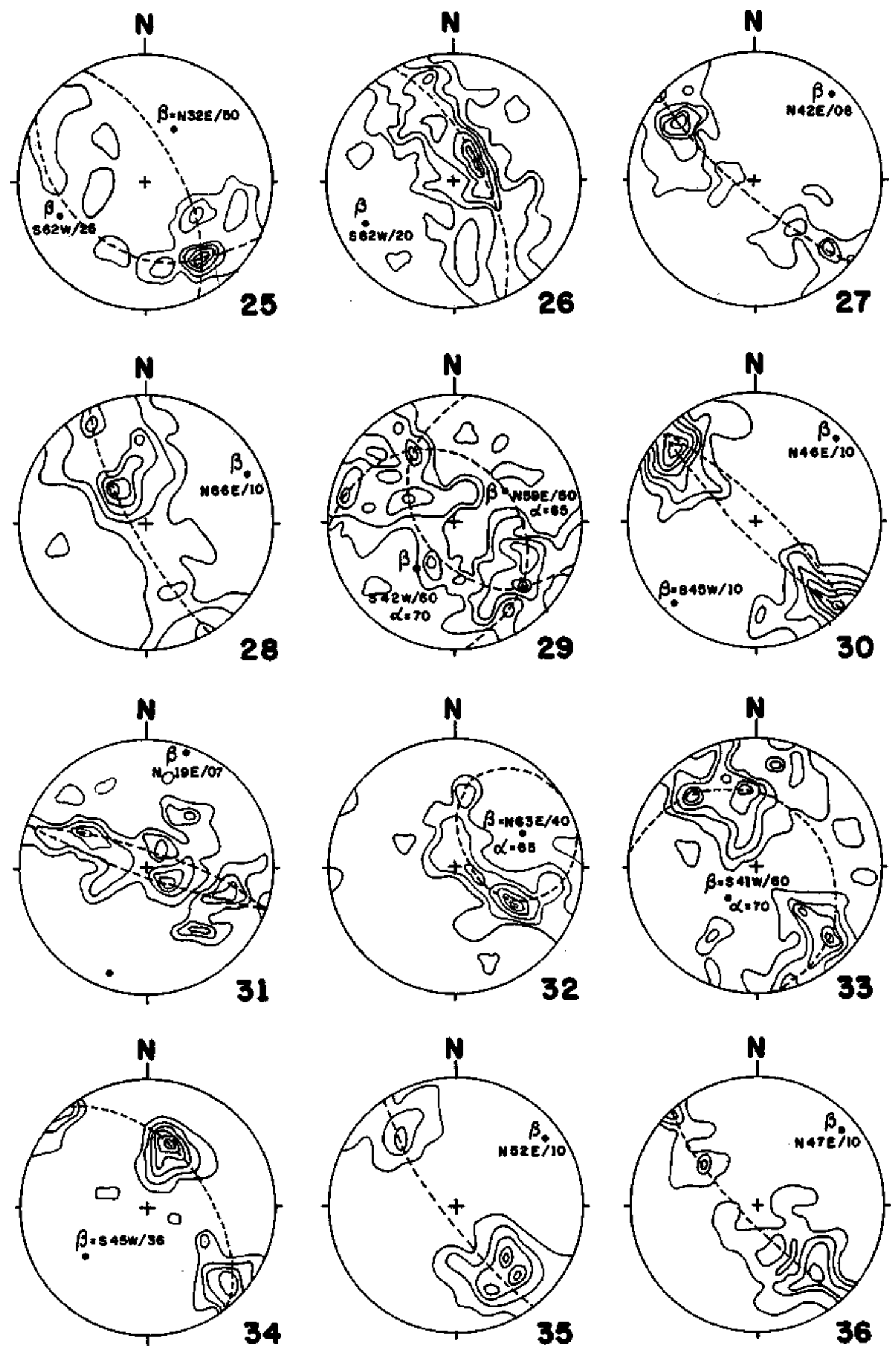

Figura 2 - Continuação

por camadas mais resistentes ao intemperísmo e pelas falhas de cavalgamento anteriormente formadas, pertencem a esse sistema, como são os casos, por exemplo, das Antiformas do Setuva, do Cerne, do Rio Caetê etc., como será discutido adiante.
A denominação de Sistema de Dobramento Apiaí para englobar essas dobras (dobras $D_{2}$ ) foi proposta por Fiori (1 991) já que foram dobras semelhantes a esses tipos que levaram Hasui et al. (1975) a definir a chamada "Faixa de Dobramen- 


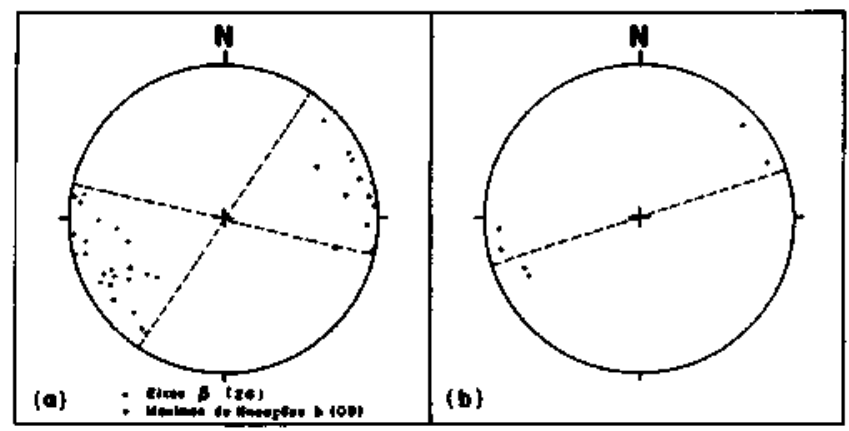

Figura 3 - Eixos $\beta$ e máximos de lineações. a. em toda a área do Bloco $\boldsymbol{E} ; \boldsymbol{b}$. na área de domínio da Antiforma do Setuva

Figure 3 - $\beta$ axes and lineation concentrations, a. in the whole Tectonic Block E area; $\mathbf{b}$. in the Setuva Antiform area

tos Apiaí", caracterizada em sua figura 3 por grandes dobras, a muitas das quais, inclusive, se associam intrusões graníticas. Correspondem às dobras da fase $\mathrm{F}_{2}$ desses autores, e respondem pela atual disposição espacial da foliação $\mathrm{Sj}$, gerada em fase anterior.

ANÁLISE GEOMÉTRICA DO SDA A área estudada, conforme já referido, foi subdividida em três grandes blocos tectônicos, denominados de C, D e E, limitados pelas Falhas de Morro Agudo e da Lancinha. Cada um desses blocos, por sua vez, apresenta uma subdivisão interna, em sub-blocos ou mantos, limitados por falhas de cavalgamento e/ou transcorrentes e dentro dos quais foram elaborados diagramas de pólos de $\mathrm{S}_{1} \mathrm{e} / \mathrm{ou} \mathrm{S}_{0}$.

A divisão da área em blocos tectônicos e mantos acha-se representada nas figuras 1 e 5 . Os números na figura 1 indicam os respectivos estereogramas, apresentados na figura 2. Ao todo foram tratados cerca de 2.300 dados estruturais entre planares e lineares, que evidenciam padrões de deformação nem sempre simples, resultantes de deformações superpostas, (ver também Quadro 1).

1. BLOCO $\boldsymbol{E}$ Este bloco situa-se a sul da Falha da Lancinha e corresponde à área de ocorrência da Formação Capiru. De modo geral, ps pólos de S, mostram uma distribuição em guirlanda parcial e, em alguns casos, em guirlanda completa, com os exemplos mais notáveis desses últimos representados pelos estereogramas 13, 19, 21, 26 e 28. Em todos os casos, é possível determinar estatisticamente o eixo de dobramento em cada subárea, obtendo-se direções entre N34E e N96E, com caimentos ora para sudoeste, ora para nordeste, mas com predominância dos primeiros (Fig. 3a). Os valores dos caimentos dos eixos $\beta$ apresentam uma variação não muito grande, entre 0 e $30^{\circ}$. A julgar pelo ângulo interflanco que pode ser recuperado em diversos estereogramas, as dobras mostram-se geralmente fechadas em perfil, com valores médios da ordem de $30-40^{\circ}$.

A estrutura mais importante do Bloco E é representada pela Antiforma do Setuva, que praticamente domina toda a área de ocorrência da Formação Capiru. Acha-se bem evidenciada pelos estereogramas de números $1,9,12,17,26$, 28 , cujas subáreas contém o traço axial dessa estrutura; os valores de $\beta$ fornecidos pelos estereogramas estão representados na figura $3 \mathrm{a}$ e, pelo método da dispersão dos eixos (Henry 1976), obtém-se a atitude média de seu plano axial, em tomo de N70E.

O eixo da antiforma parece variar pouco, tanto em direção como em caimento, havendo tendência à horizontalização do mesmo junto ao núcleo e, na terminação sudoeste da es-

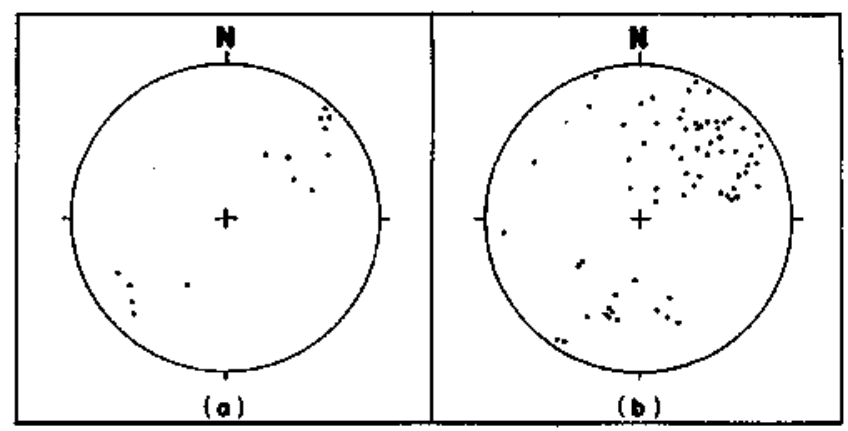

Figura 4 - Distribuição dos eixos $\beta$ (14) no Bloco Tectônico $D(4 a)$ e de eixos $b(70)$ de dobras presentes nesse mesmo Bloco (4b)

Figure 4 - Structural orientation data in the D Tectonic Block, a. $14 \beta$ axes; $b$. $70 \mathrm{~b}$ fold axes

trutura, próximo à Bateias. No restante da área, o caimento não supera $20^{\circ}$, com uma direção média em torno de N60E. O flanco norte da antiforma é representado pelos estereogramas de números 8,14 e 16, enquanto o flanco sul, é representado pelos de números $2,5,6,7,10,13,18,19$ e 21 , e mostram concentrações indicativas da predominância absoluta de um flanco sobre o outro. Todos esses estereogramas, entretanto, evidenciam um padrão de dobramento com geometria similar ao da Antiforma do Setuva, porém, em escalas menores e disperso por toda a área, o que vem a demonstrar que essa estrutura pode ser classificada mais apropriadamente de anticlinório. Afigura 1, deixa bem evidente também que grande parte do seu flanco norte está truncado pela Falha da Lancinha.

2. BLOCO D Neste bloco, domina a Formação Votuverava e, de modo geral, a foliação $\mathrm{S}$, ocorre paralelizada à $\mathrm{S}_{0}$. Os diagramas de pólos de $\mathrm{S}$, mostram padrões similares àqueles do Bloco E, com guirlandas parciais e completas, fornecendo eixos estatísticos B direcionados ora para sudoeste, ora para nordeste, com baixos valores de caimento, inferiores a $40^{\circ}$. Há, entretanto, certa predominância de caimentos para o quadrante nordeste.

No Bloco $\mathrm{D}$, há maior recorrência de estereogramas que permitem o traçado de guirlandas duplas, como são os casos por exemplo, daqueles de números 15, 25 e 29, como também o traçado de círculos menores, indicativos de distribuição cônica, a exemplos daqueles de números 23,24, 29 e 33. Diagramas desse tipo indicam complicações estruturais, evidenciando padrões de superposição que não são vistos no Bloco $\mathbf{E}$, e que implicam em ondulações mais acentuadas dos eixos e perda da cilindricidade das dobras, ao menos localmente.

A presença de dobras cônicas pode estar relacionada a dobramentos superpostos ou então a efeitos geométricos devidos a falhamentos sobre estruturas pré-existentes. No caso do diagrama 29, a causa mais provável parece ligada aos efeitos somados das Falhas do Cerne, de Morro Agudo e da intrusão do Granito do Cerne, que teriam complicado a geometria dessa subárea; nos casos dos diagramas 23 e 33, a causa mais provável parece ligada às transcorrências da Lancinha, Morro Agudo e do Cerne, enquanto para o diagrama 24 , a causa é menos evidente, podendo estar relacionada a dobras de arrasto associadas às Falhas do Votuverava e do Betara, ambas de cavalgamento, redobradas posteriormente pelo SDA.

O estereograma 32 mostra uma distribuição de pólos de S1 em litologias atribuíveis ao Grupo Setuva (Formação Perau). A distribuição se adapta perfeitamente a um padrão de dobras cônicas, com eixo $\beta$ de atitude N63E 40NE, e com geratriz perfazendo um ângulo de $40^{\circ}$ com os pólos de $\mathrm{S}$,. $\mathrm{E}$ 


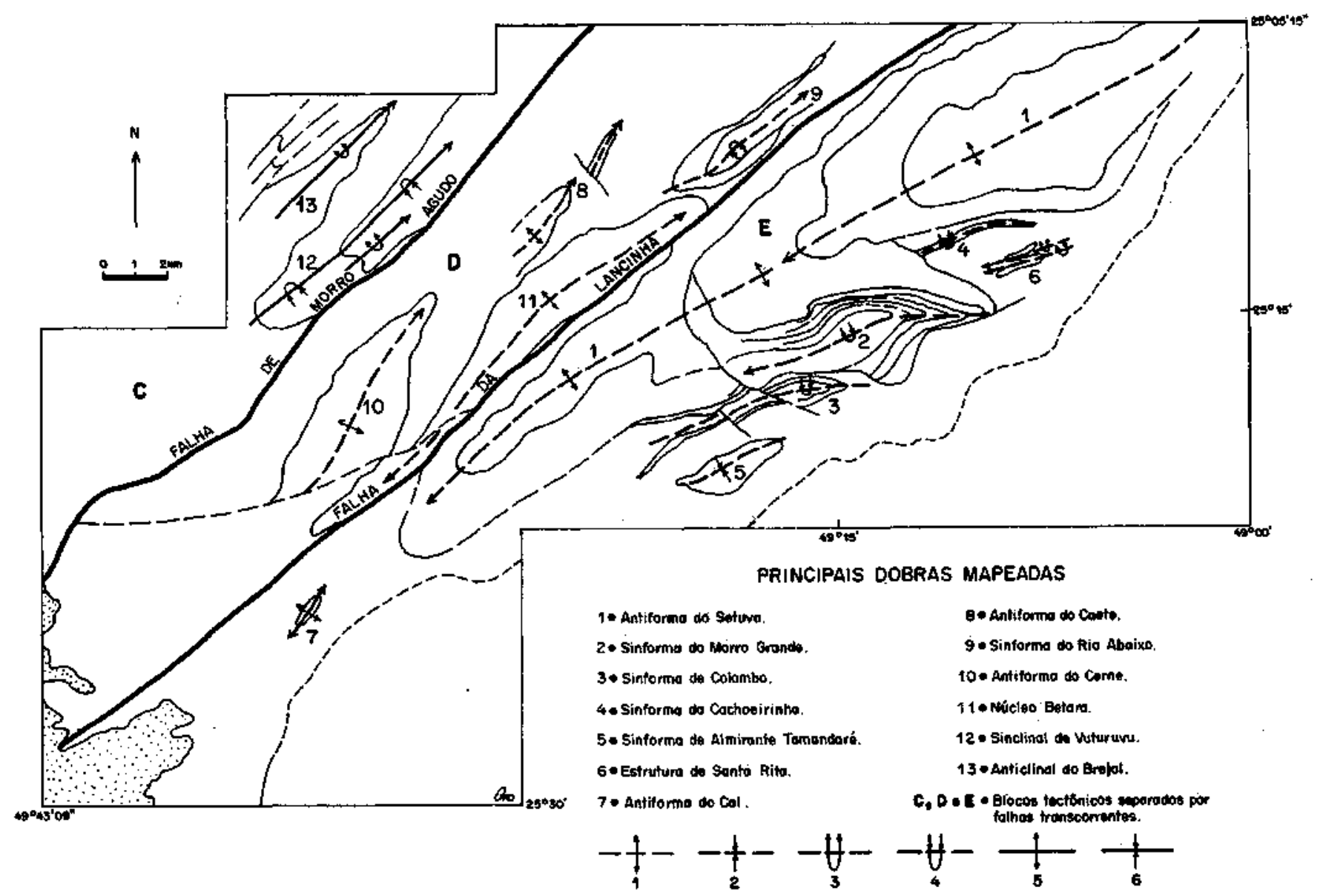

Figura 5 - Mapa estrutural com as principais dobras da área representadas. Símbolos estruturais: 1 e 2 - traço axial de antiforma e sinforma, com indicação de caimento do eixo. 3 e 4- traço axial de antiforma e sinforma, comflancos mergulhando para o mesmo quadrante e com indicação de caimento do eixo. 5 e 6-traço axial de anticlinal e sinclinal, com indicação de caimento do eixo

Figure $\mathbf{5}$ - Structural map with the major regional folds represented. Structural symbols: $\mathbf{1}$ and $\mathbf{2}$ - trace of the hinge surface of a upright plunging antiform and synform. $\mathbf{3}$ and $\mathbf{4}$ - trace of the hinge surface of overturned plunging antiform and synform. $\mathbf{5}$ and $\mathbf{6}$ - trace of the hinge surface of upright plunging anticline and syncline

interessante ressaltar que essa subárea tem seu limite norte feito pela Falha do Cerne, a qual pode ter induzido deformações adicionais. Os diagramas de números 25 e 27 representam a distribuição de pólos de $\mathrm{S}$, dentro do Núcleo Betara, estes porém, com padrões bastante similares àqueles da Formação Votuyerava, evidenciando concordância estrutural entre litologias dos Grupo Açungui e Setuva em base a essa foliação. Os diagramas 22 e 23, apesar de mostrarem um padrão de distribuição de pólos similar aos demais, apresentam maior concentração de dados no quadrante sudeste, fazendo supor a presença de dobras assimétricas, com vergência para sudeste.

A distribuição dos eixos fi no Bloco $\mathbf{D}$ é representada pela figura 4a. O padrão é bastante regular, com direção preferencial NE-SW e baixos valores de caimento. A figura $4 \mathrm{~b}$ mostra a distribuição de todos os eixos b de dobras do SDA recuperadas nesse mesmo bloco. O padrão é bastante consistente com aquele da figura $4 \mathrm{a}$, mas mostra de forma mais evidente, o predomínio de caimentos para nordeste.

3. BLOCO C Os dados estruturais referentes a esse Bloco são ainda escassos, havendo necessidade de estudos mais detalhados. Os estereogramas de números 35 e 36 foram elaborados por Dias e Salazar Jr (1987), com o primeiro representando pólos de $\mathrm{S}_{0}$ obtidos na Formação Antinha e o segundo, pólos de $\mathrm{S}_{1}$, na Formação Água Clara (Seqüência Serrinha). O diagrama 31 reflete a distribuição de pólos de $\mathrm{S}$, na Seqüência São Silvestre, da mesma Formação Água Clara. Fato que chama de imediato a atenção é a semelhança entre os estereogramas 35 e 36, demonstrando concordância espacial entre o acamamento da Formação Antinha e a foliação $\mathrm{S}$, da Seqüência Serrinha. $\mathrm{O}$ eixo fi fornecido pelo diagrama 35 , aliada à forma do fechamento da estrutura, mostra a estruturação da Seqüência Antinha em sinclinal.

AS PRINCIPAIS DOBRAS DA ÁREA Diversas dobras foram mapeadas na área e estudadas com mais detalhes. No Bloco E, a sul da Lancinha, aparecem a Antiforma do Setuva, que é a maior estrutura reconhecida, e as Sinformas do Morro Grande, Colombo, Cachoeira, Almirante Tamandaré, Estrutura de Santa Rita e Antiforma do Cal. No Bloco D, entre as Falhas de Morro Agudo e da Lancinha, aparecem o Núcleo Betara, as Antiformas do Cerne e Caetê e a Sinforma do Rio Abaixo. Já, no Bloco C, comparecem a Sinclinal do Vuturuvu e a Anticlinal do Brejal (Fig. 5).

$\mathrm{O}$ estudo dessas estruturas se baseou na distribuição dos pólos da foliação $\mathrm{S}$, (paralela a $\mathrm{S}_{0}$ ), e na forma geral com que aparecem no mapa geológico. Com os dados de $\mathrm{S}$, foram elaborados diagramas de equiárea para cada estrutura, o que permitiu a definição do eixo estatístico fi, a sua provável simetria e vergência estrutural. Nem todas as dobras estudadas pertencem ao Sistema de Dobramento Apiaí, algumas estando relacionadas a retrocavalgamentos, por exemplo, como será visto em seguida. 


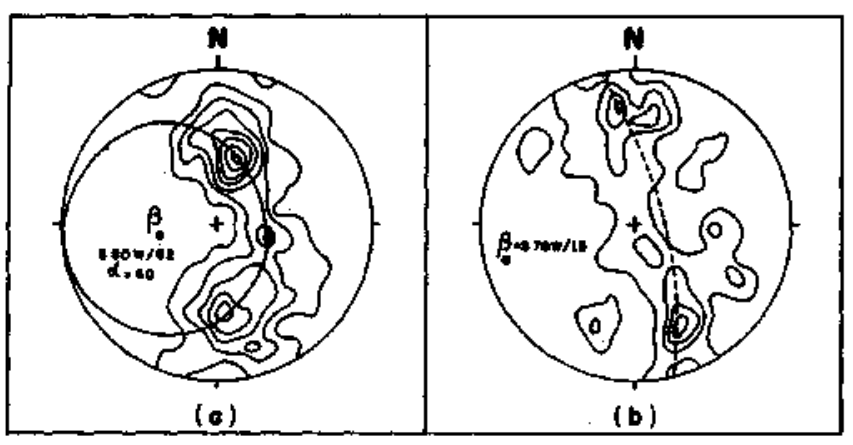

Figura 6 - Padrões de distribuição de pólos de $S_{t}$ na Antiforma do Setuva. a. 391 pólos, distribuídos ao longo de toda a estrutura. Curvas de 1-2-3-4-5-6 e 7\% por 1\% de área. b. 84 pólos da zona apical da mesma estrutura. Curvas de 1-3-5-7\% por 1\% de área

Figure 6 - Distribution patterns of S, poles from the Setuva Antiform. a. $391 \mathrm{~S}$, poles, along the structure. Contour intervals are $1-2-3-4-5-6-7 \%$ per $1 \%$ area; b. $84 \mathrm{~S}$, poles from the apical zone of same structure. Contour intervals are 1$3-5-7 \%$ per $1 \%$ area

1. ANTIFORMA DO SETUVA A zona periclinal dessa estrutura é facilmente identificável em fotografias aéreas, devido ao contraste de resistência à erosão entre o conjunto de gnaisses, xistos e migmatitos do embasamento e os mármores da Formação Capiru, situados à sua volta. Apresenta um traço axial de direção aproximada N60E, com caimento do eixo voltado para sudoeste. Tem uma extensão de mais de 50 $\mathrm{km}$ e define as principais linhas geométricas do Bloco E. E mais apropriadamente uma "meia antiforma", já que seu flanco norte encontra-se parcialmente seccionado pela Falha da Lancinha.

Diversas falhas de cavalgamento foram dobradas por essa estrutura, como são os casos das Falhas de Tranqueira, Pessegueiro, Queimadinho e Setuva. Estas duas últimas revestem-se de importância particular por representarem as zonas de descolamento da Formação Capiru em relação ao Grupo Setuva e ao Complexo Pré-Setuva (Ebert 1971), respectivamente. Caracterizam-se pela presença de cataclasitos, milonitos e até ultramilonitos, em faixas de largura variável. Achatamento e estiramento mineral, rotações de minerais com sombras de pressão assimétricas e simétricas, foliações S-C e deformação heterogênea são feições comuns em lâminas petrográficas dessas zonas. De um modo geral, as rochas pré-existentes foram transformadas em xistos ou filitos, devido à intensidade da deformação atuante no processo tectônico que originou os principais cavalgamentos.

A Antiforma do Setuva é desenhada pela foliação $S$, gerada por transposição de $\mathrm{S}_{0}$, durante o evento de cavalgamento que atingiu quase todo o Grupo Apungui. Em locais de concentração da deformação, desenvolvem-se zonas de cisalhamento, onde a $S_{1}$ é tipicamente uma foliação do tipo $\mathrm{C}$ (cisalhamento), com o $\mathrm{S}$ disposta a ângulos geralmente inferiores a $25^{\circ}$. As falhas de cavalgamento representam zonas de cisalhamento em escala maior, desenvolvidas em condições rúpteis-dúcteis.

Em posição plano axial dessa estrutura, aparece a foliação $\mathrm{S}_{3}$, não tão proeminentemente desenvolvida como a $\mathrm{S}_{1}$, tratando-se mais adequadamente de uma clivagem de crenulação. Nem sempre está presente em todos os afloramentos, sendo preferencialmente vista nos xistos e filitos posicionados no limite Acungui/Embasamento e em litologias de granulometria bem fina. Tem direção nordeste e posição vertical ou subyertical.

Conforme visto anteriormente, os diversos diagramas de pólos de $\mathrm{S}_{1}$ em diferentes seções da Antiforma do Setuva, mostram eixos $\beta$ com caimentos em torno de $20^{\circ}$ para sudoeste, mas com tendência à horizontalizacão e mesmo in-

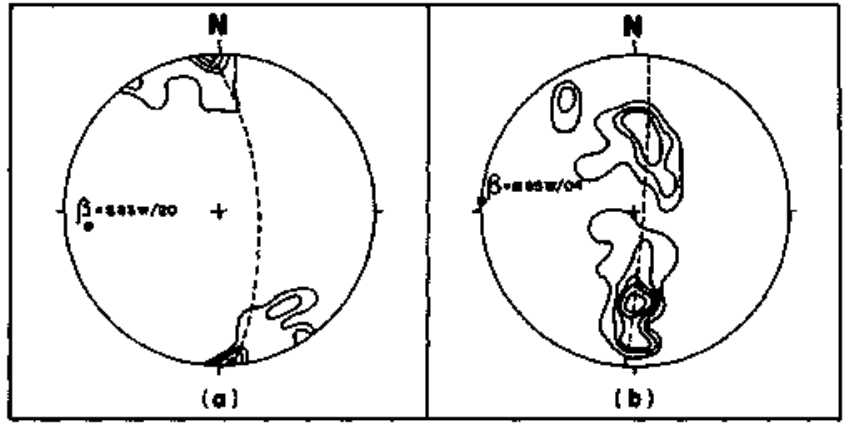

Figura 7-a. Distribuição de 26 pólos de $S$, na Sinforma de Colombo. Curvas de 5-10-15 e 20\% por 1\% de área. b. Distribuição de 60pólos de $S$, na Sinforma da Cochoeirinha. Curvas de 2-4-6-8 e 10\% por 1\% de área Figure 7 - a. $26 \mathrm{~S}$, poles distribution from de Colombo Synform. Contour intervals are $5-10-15-20 \%$ per $1 \%$ area. b. $60 \mathrm{~S}$, poles distribution from the Cachoeirinha Synform. Contour intervals are 2-4-6-8-10\% per 1\% area

versão no sentido do caimento, junto as suas partes terminais. O diagrama onde foram lançados todos os pólos de $S_{1}$ obtidos ao longo dessa estrutura, mostra uma distribuição que melhor se adapta a um cone ao invés de um cilindro (Fig. 6a), com eixo $\beta$ de atitude $\mathrm{S} 80 \mathrm{~W} / 62 \mathrm{SW}$ e geratriz a $60^{\circ}$.

Dobras cônicas são típicas para áreas que sofreram vários eventos de deformação, quando então perderam sua original cilindrícidade (Evans 1963). É possível que esse efeito, no caso da Antiforma do Setuva, tenha como causa a Falha da Lancinha ou reflita o resultado de dobramento de uma superfície irregular preexistente.

Considerando-se apenas a antiforma, em sua zona de contato Acungui/Embasamento, a distribuição de pólos de $S_{1}$ adapta-se a um padrão de dobramento cilíndrico, com eixo $\beta$ de atitude S78W 15SW (Fig. 6b), o que, de certa forma, coincide com a atitude média de S70W $15 \mathrm{SW}$ para o eixo, desde sua porção média até sua terminação sudoeste. No núcleo da antiforma, onde aflora o Complexo Pré-Setuva, o eixo tende à suborizontalizacão, com caimentos iguais ou menores que $10^{\circ}$, mas com algumas inversões para nordeste, demonstrando uma certa ondulação. É improvável entretanto, dado á sua suavidade, que essa ondulação seja devida a uma fase de dobramento superposta. Mais provavelmente esse fenômeno está ligado ao desenvolvimento desigual da estrutura, de vez que envolve pacote de rochas com comportamentos mecânicos diferentes ou então corresponde a efeitos localizados da Falha da Lancinha.

2. SINFORMA DE MORRO GRANDE Apresenta um traço axial suavemente encurvado, tendo de sua metade para leste uma direção aproximada E-W e de sua metade para oeste, uma direção em torno de N60E. O eixo megiilha para sudoeste, no sentido da abertura do $\mathrm{V}$, caracterizando assim, uma estrutura sinformal. O truncamento do seu flanco sul pela Falha de Morro Grande é bem evidenciado em fotos aéreas, especialmente em um trecho a norte-noroeste de Colombo.

O diagrama da distribuição de pólos de S, (Diagrama 13, Fig. 2) obtidos principalmente na zona apical da estrutura, mostra uma distribuição em guirlanda, com eixo fi de atitude S89W/20SW. Mais para oeste, em sua porção média, a distribuição dos pólos de $\mathrm{S}$, se dá segundo uma guirlanda parcial, com eixo de atitude S50W/40SW, como mostra o diagrama 18. Geometricamente, é uma dobra isoclinal ou fechada, com ângulo inter-flanco da ordem de $25-30^{\circ}$, e eixo encurvado, como de resto deixa entrever a forma de seu traço axial.

A Sinforma de Morro Grande é uma estrutura geológica complexa, tratando-se, na verdade, de uma dobra-falha as- 


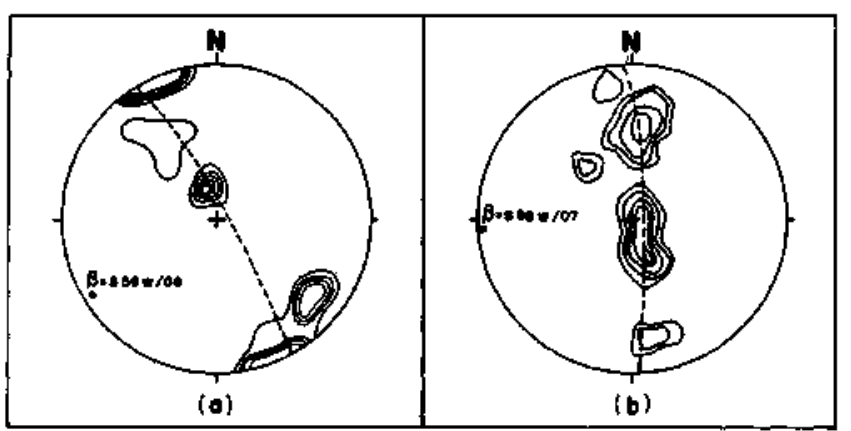

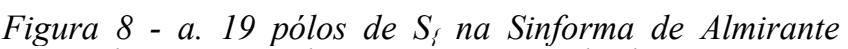
Tamandaré. Curvas de 4-6-8 e 10\% por l\%de área, e b. 20 pólos de $S_{t}$ na Estrutura de Santa Rita. Curvas de 5-10-1520 e $25 \%$ por $1 \%$ de área

Figure 8 - a. 19 S, poles from Almirante Tamandaré Synform. Contour intervals are $4-6-8-10 \%$ per $1 \%$ area. b. 20 S, poles from Santa Rita Structure. Contour intervals are $5-10-15-20-25 \%$ per $1 \%$ area

sociada à Falha de Morro Grande e com plano axial inclinado para sul. Posteriormente, foi afetada pelo SDA, posicionando-se a partir daí no flanco sul da Antiforma do Setuva, podendo este fato ser avaliado por meio da relação geométrica da foliação $\mathrm{S}_{3}$ que, na verdade, transecta a ambos os flancos da sinforma. Conseqüentemente, não pode ser geneticamente relacionada ao SDA, mas sim ao SCA, e mais especificamente, a falhas de retrocavalgamentp, que são algo mais tardias que aquelas de cavalgamento (Fiori 1992c).

3. SINFORMA DE COLOMBO É uma dobra posicionada entre duas falhas de retrocavalgamento (Falhas de Morro Grande e de Almirante Tamandaré), sendo também relacionada ao SCA. Seu traço axial tem direção aproximadamente E-W, infletindo-se para NE-SW a partir do Rio Barigui para sudoeste. O diagrama de pólos de S, (Fig.7a) mostra uma guirlanda parcial, com eixo estatístico B de atitude S83W 20SW, bastante semelhante ao da Sinforma de Morro Grande. O ângulo inter-flanco é praticamente zero, tratando-se de uma dobra isoclinal, com plano axial voltado para sul. Da mesma forma que a estrutura anterior, está também posicionada no flanco sul da Antiforma do Setuva.

4. SINFORMA DA CACHOEIRINHA No mapa, seus flancos são praticamente paralelos, apresentando um traço axial suavemente curvo, variando de N65E a E-W. A distribuição dos pólos de $\mathrm{S}$, permite definir uma guirlanda parcial (Fig. Tb), indicativa de dobramento aberto, com ângulo interflanco da ordem de $80^{\circ}$. O eixo B tem atitude N85W 4SW, com o baixo ângulo de caimento explicando o aparente paralelismo dos flancos. Trata-se de uma dobra assimétrica, com predomínio do flanco com mergulho para norte. Posiciona-se no flanco sul da Antiforma do Setuva e parece estar relacionda às Falhas do Setuva e do Queimadinho, pertencendo assim ao SCA.

5. SINFORMA DE ALMIRANTE TAMANDARÉ E s t a estrutura é evidenciada a nível de fotografias aéreas por uma camada de filitos com intercalações de quartzitos mais resistente ao intemperismo, bordejando um núcleo central de mármore cinza. Tem forma ovalada, com eixo exibindo caimento duplo. O diagrama de pólos (Fig. 8a) foi elaborado com poucos dados (nessa área os afloramentos são escassos) e portanto pouco conclusivo. Entretanto, parece haver tendência à distribuição em guirlanda, em torno de um eixo $B$ de atitude S58W 8SW. Pelo fato de causar dobramento na Falha da Colônia Venâncio, foi atribuída ao Sistema de Dobramento Apiaí.
6. ESTRUTURA DE SANTA RITA E bem evidenciada em fotografias aéreas ao ser delineada por camadas de quartzito, mais resistentes ao intemperismo, embutidas em filitos. Constitui-se de uma sinforma e uma antiforma pareadas, tendo uma lente de mármores dolomítico na zona apical da segunda. O diagrama de pólos de S, (Fig. 8b) mostra uma distribuição em guirlanda incompleta, com eixo $\beta$ de atitude S88W 7SW. Possivelmente com um número maior de dados, a guirlanda possa vir a ser inteiramente desenhada; porém, há dificuldades de se encontrar bons afloramentos no local, que inclusive é de difícil acesso. O ângulo interflanco médio dessas dobras gira em torno de $45^{\circ}$, tratando-se assim de uma estrutura fechada. Pelo fato de não estar relacionada a nenhuma falha de cavalgamento, considera-se que esteja associada ao SDA.

7. ANTIFORMA DO CAL É uma estrutura de pequeno porte, em forma de domo algo alongado, em cujo núcleo aflora um pequeno corpo granítico de cor rosa-claro bastante deformado, e rochas migmatíticas do embasamento do Grupo Açungui. Bordejando esse núcleo, comparece uma camada mais espessa de quartzito e lentes de mármore da Formação Capim. Seu eixo $\beta$ tem atitude N46E 10NE, mas é possível ainda traçar outra guirlanda e obter um segundo eixo $\beta$ de atitude S45W 10SW, o que demonstra a forma algo dômica dessa estrutura (Diagrama 30, Fig. 2). Seu ângulo interflanco é da ordem de $30^{\circ}$ e está relacionada ao Sistema de Dobramento Apiaí.

8. ANTIFORMA DO CAETE $\hat{E}$ Situa-se no Bloco D e foi reconhecida anteriormente por Scholl (1981), que lhe deu o nome de Anticlinório do Caetê. Encontra-se truncada aproximadamente em sua parte média por uma falha normal de direção noroeste, que causou soerguimento da sua porção sudoeste e rebaixamento da porção nordeste. Tem traço axial algo ondulado, mas com direção geral N45E. O diagrama de pólos de $\mathrm{S}_{1}$ mostra uma distribuição complexa, com vários máximos bem individualizados (Diagrama 24, Fig. 2), mas que podem ser ajustados a uma distribuição cônica, com eixo $\beta$ de atitude, N45E 40NE. A dobra tem assim geometria cônica e geratriz em torno de $75^{\circ}$, estando aparentemente relacionada ao Sistema de Dobramento Apiaí.

9. SINFORMA DO RIO ABAIXO Também esta estrutura foi reconhecida por Scholl (1981), à qual se atribuiu a denominação de Sinclinório do Rio Abaixo. Seu traço axial tem direção geral em torno de N50E. O diagrama de pólos de $S_{1}$ mostra uma distribuição em guirlanda parcial, relativamente bem definida, com eixo $\beta$ de atitude N58E $28 \mathrm{NE}$ (Diagrama 20, Fig. 2). A dobra é do tipo fechada, com ângulo inter-flanco da ordem de $50^{\circ}$, estando relacionada ao Sistema de Dobramento Apiaí.

10. ANTIFORMA DO CERNE Esta estrutura é conhecida desde muito tempo, abrigando em seu interior o granito do mesmo nome. É uma estrutura alongada, em forma elíptica, truncada na sua porção sul pela Falha do Cerne, de natureza transcorrente. E circundada por quartzitos e filitos, que realçam sua forma devido às diferenças em resistência à erosão. O diagrama de $\mathrm{S}_{1}$ (Diagrama 29, Fig. 2) mostra pequenas concentrações esparsas, que no entanto permitem a interpretação de uma dobra cônica, com valores de $\beta$ e $\beta^{\prime}$ respectivamente de N59E 50NE (com geratriz a $65^{\circ}$ ) e S42W 60SW (com geratriz a $70^{\circ}$ ). Relaciona-se ao Sistema de Dobramento Apiaí.

11. NÚCLEO BETARA Sob esta denominação, entendese um conjunto aflorante de rochas atribuíveis ao Complexo Pré-Setuva e à Formação Perau (Fritzpns Jr et al. 1982, Pierkarz 1984), e que se estende desde Rio Branco do Sul até 

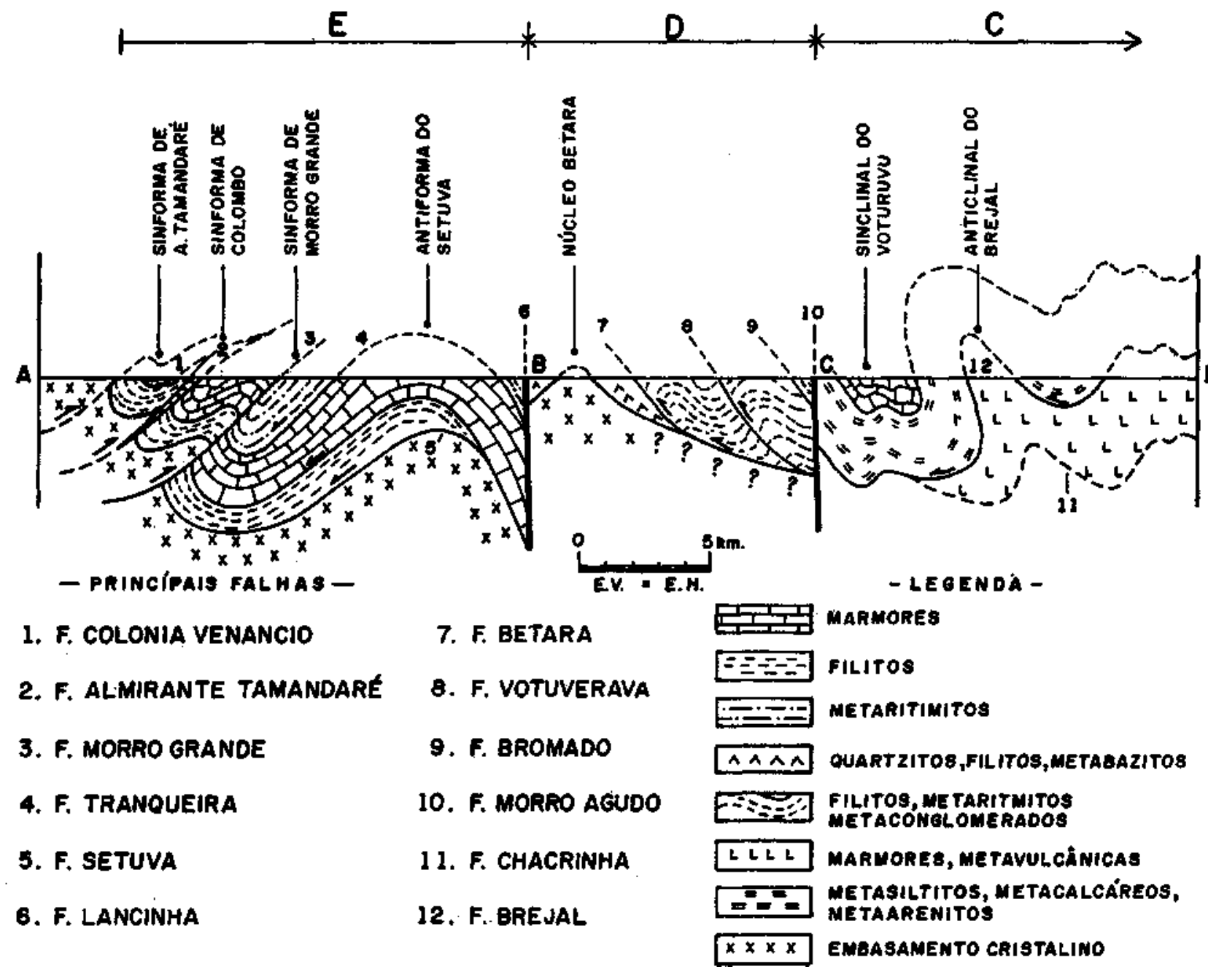

Figura 9 - Seção geológica A-B-C-D, evidenciando as principais falhas e estruturas da área. Localização da seção na figura l, visada de NE para SW. Os Blocos Tectônicos $\boldsymbol{C}, \boldsymbol{D}$ e $\boldsymbol{E}$, limitados pelas falhas da Lancinha e de Morro Agudo, estão assinalados no alto da figura

Figure 9 - A-B-C-D structural cross-section,throught the studied area, showing the principal faults and folds. The $\mathbf{C}, \mathbf{D}$, and $\mathbf{E}$ Tectonic Blocks, limited by the Lancinha and Morro Agudo transcurrent faults, are represented on the top of the figure. For localization of section, see fig. 1 (further details in the text)

Ouro Fino. Tem forma grosseiramente elíptica, estando limitado a norte pela Falha do Betara, de cavalgamento, e a sul pela Falha da Lancinha. O diagrama de pólos de S, mostra uma distribuição complexa, permitindo duas interpretações diferentes. Uma possibilidade é o ajustamento de pólos segundo uma guirlanda de eixo $\beta$ com atitude N32E 50NE e outra, com ajustamento a uma guirlanda de eixo $\beta^{\prime}$ de atitude S64E 25SE (Diagrama 25, Fig. 2). O segundo está mais próximo ao valor do eixo encontrado por Pierkarz (1984), cuja atitude é S79W 27SW. Possivelmente, os dois eixos encontrados reflitam simplesmente a natureza braquiantiformal dessa estrutura, com caimentos duplos. A maior concentração de pólos no quadrante sudeste indica uma marcante assimetria, com predomínio de mergulhos para noroeste. Considerou-se esta estrutura ligada ao SDA.

12. SINCLINAL DE VUTURUVU E ANTICLINAL DO BREJAL Estas estruturas parecem coincidir respectivamente com o Sinclinório de Vuturuvu e Anticlinório de São Vicente, na denominação de Scholl (1981). Trata-se de estruturas com planos axiais inclinados para noroeste e traços axiais de direção em torno de N40-45E. A primeira abriga em seu interior um conjunto de metassedimentos pouco metamorfizados, denominados de Seqüência Antinha (Pontes 1982, Dias \& Salazar Jr. 1987) ou Formação Antinha, Fiori (1982o), enquanto a segunda expõe parte da Formação Água
Clara (Marini et al. 1967, Marini 1970). Os diagramas de número 35 e 36 , anteriormente referidos, representam respectivamente essas duas estruturas, desenhando guirlandas parciais e eixos estatísticos com atitudes de N52E 1 ONE e N47E 10NE.

CONSIDERAÇÕES FINAIS A disposição espacial da foliação $\mathrm{S}$, nas diversas subáreas dos blocos tectônicos $\mathbf{C}, \mathbf{D}$ e $\mathbf{E}$ mostra padrões semelhantes entre si, evidenciando um estilo de dobramento praticamente igual nos três blocos. Os eixos são direcionados para nordeste, com caimentos tanto para nordeste como para sudoeste, a ângulos, no geral, inferiores a $20^{\circ}$. Parece haver predomínio de caimentos para sudoeste no bloco E, área de ocorrência da Formação Capiru, e de caimentos para nordeste nos blocos $\mathbf{C}$ e $\mathbf{D}$, que são as áreas de ocorrência das Formações Antinha e Votuverava, respectivamente.

As estruturas maiores, cartografadas e investigadas estruturalmente, podem ser reunidas em dois grupos distintos. Um é constituído por dobras-falha, associadas principalmente a retrocavalgamentos, como são os casos das Sinformas do Morro Grande e de Colombo ou então a cavalgamentos, como é o caso da Sinforma da Cachoeirinha, enquanto ao outro relacionam-se as estruturas ligadas ao Sistema de Dobramento Apiaí, como são os casos das Antiformas do Setuva, Caetê, Cerne, Cal, Brejal, Núcleo 
Betara e as Sinformas de Almirante Tamandaré, Rio Abaixo, Vuturuvu, além da Estrutura de Santa Rita. As estruturas do primeiro grupo foram identificadas no bloco E e estão posicionadas no flanco da Antiforma do Setuya, pertencente ao segundo grupo, o que bem demonstra a idade relativa entre ambos. Na seção apresentada na figura 9 são ressaltadas as principais feições estruturais, acima discutidas, segundo uma seção A-D, de direção sudeste-noroeste. Os blocos tectônicos C, D e E, as principais dobras estudadas, as falhas de cavalgamento e de retrocavalgamento, e as relações estruturais entre essas diferentes estruturas são colocadas em evidência.

De um modo geral, os diagramas de pólos de $\mathrm{S}_{1}$ das diversas estruturas analisadas determinam padrões bastante semelhantes. Seus eixos estão direcionados para nordeste-sudoeste, com caimentos geralmente inferiores a $20^{\circ}$. Algumas mostram padrões mais complicados, mas que podem ser ajustados a distribuições cônicas, indicando a presença de dobras com esta geometria, mas com eixos ainda direcionados para NE-SW e planos axiais subverticais. Em pelo menos dois casos, há intrusões graníticas associadas a dobras pertencentes ao Sistema de Dobramento Apiaí.

Tendo em vista a direção nordeste-sudoeste dos eixos, e a posição vertical ou subvertical dos planos axiais das dobras do SDA, deduz-se que foram geradas por um esforço compressivo de direção NW-SE. Entretanto, pode-se ainda especular com duas hipóteses distintas para a origem desse esforço.

A primeira hipótese leva a considerar o esforço como de segunda ordem, relacionado ao evento tectônico causador das falhas transcorrentes. Nesse caso, as dobras teriam se formado como conseqüência da movimentação diferencial das principais transcorrências, que, por serem dextrógiras, induziram o surgimento de um esforço de segunda ordem, direcionado segundo NW-SE. A disposição dos eixos e dos planos axiais das dobras do SDA é assim perfeitamente compatível com esse modelo (ver, p.ex., Wilcox et al 1973), podendo ser consideradas como dobras escalonadas, associadas às transcorrências. Esta hipótese, entretanto, tem contra si a disposição espacial do eixo e do plano axial da Antiforma do Setuva, que não é compatível com movimentação lateral-direita.

A segunda hipótese leva a considerar a origem das dobras por atuação de um esforço compressivo de primeira ordem, de direção NW-SE, sem vinculação com o evento de transcorrência.

Ambas as hipóteses levam em conta processos deformacionais basicamente diferentes. A primeira implica em deformação não-coaxial e a segunda, em deformação coaxial. Esta última tem contra si o fato do esforço compressivo, que poderia atuar em qualquer direção, estar coincidentemente orientado na direção previsível do esforço de segunda ordem, associado ao evento de transcorrência.

Regionalmente (ver, p.ex., Mapa Geológico do Estado do Paraná, Biondi 1989), observa-se que o ângulo entre os traços axiais dessas dobras e as principais transcorrências é variável, tendendo a zero nas adjacências das falhas, mas aumentando gradualmente com o distanciamento das mesmas, o que ocasiona uma suave inflexão do traço axial, compatível com movimentação dextrógira. Este fenômeno é previsível e indicativo de uma gradual diminuição da intensidade da deformação cisalhante à medida que aumenta a distância entre o traço axial e a falha (Ramsay \& Huber 1983). Bom exemplo disto é a Megantiforma da Serra do Cadeado (Hasui et al 1984), que aponta para uma evidente relação entre as falhas transcorrentes e as dobras do SDA, favorecendo a primeira hipótese.

Não é, entretanto, possível afirmar que todas as dobras aqui atribuídas ao SDA sejam do tipo escalonadas, associadas às transcorrências. Como exemplo, menciona-se a Antiforma do Setuva, cuja disposição do eixo em relação à Falha da Lancinha não é compatível com uma movimentação lateral-direita, mas sim com uma movimentaço lateral-esquerda. Há seguras evidências de reativação levógira ao longo da Lancinha (Scholl 1981, Fiori 1985, Soares \& Gois 1987), porém, é duvidoso que esta pudesse originar uma estrutura da envergadura da Antiforma do Setuya.

É discutível, por outro lado, a possibilidade das dobras em questão terem se formado em uma fase compressiva, advinda antes da implantação das falhas transcorrentes, como deixam entrever Hasui et al (1984). Os blocos tectônicos hoje justapostos pelas Falhas da Lancinha e de Morro Agudo deveriam se posicionar originalmente a centenas de quilômetros de distância, (e.g. Fiori 1985) e, assim, é de se esperar uma variação significativa na disposição dos elementos geométricos e no estilo das dobras, o que não foi verificado na área.

Aspecto relevante a destacar em relação às dobras do SDA é o generalizado baixo ângulo de caimento dos eixos nos três blocos (C, D e E). Esta fato é indicativo de uma pretérita disposição suborizontal da foliação $\mathrm{S}$, , originada durante o evento de cavalgamento, o que também já havia sido observado por Hasui et al (1984), na região da Megantiforma da Serra do Cadeado, admitindo a origem da foliação ligada a processo de cisalhamento dúctil de baixo ângulo de mergulho.

O predomínio de caimento dos eixos das dobras do SDA, no Bloco E, em contraposição ao predomínio do caimento para nordeste no Bloco D, ambos separados pela Falha da Lancinha, leva a pressupor um provável efeito de basculamento de blocos na direção dessa falha. Por outro lado, esse fenômeno não foi observado nos Blocos C e D, separados pela Falha de Morro Agudo. A presença de dobras com geometria cônica parece de uma forma ou outra, relacionar-se a efeitos causados por falhamentos transcorrentes.

CONCLUSÕES O Sistema de Dobramento Apiaí engloba dobras de estilos variados, mas com eixos direcionados para nordeste-sudoeste, e caimentos, no geral, inferiores a $20^{\circ}$. Na área de domínio da Formação Capina (Bloco E), há predomínio de caimentos voltados para o sudoeste, enquanto nas áreas de domínio das Formações Votuverava (Bloco D) e Antinha (Bloco C), há predomínio de caimentos para o quadrante nordeste. Algumas tem geometria mais complicada, compatível com dobras cônicas.

As dobras desse sistema são posteriores ao evento de cavalgamento que afetou o Grupo Açungui, pois são desenhadas pela foliação $S_{1}$ e pelas falhas de cavalgamento, ambas originadas durante esse primeiro evento deformativo. No campo, observou-se em alguns locais, desenvolvimento de uma foliação $S_{3}$ em posição plano axial - esta não é penetrativa por toda a área.

Diversas estruturas maiores relacionadas ao SDA foram cartografadas, como são os casos das Antiformas do Setuva, Caetê, Cerne, Cal, Brejal e o Núcleo Betara, além das Sinformas de Almirante Tamandaré, Rio Abaixo, Vuturuvu e a Estrutura de Santa Rita. Outras estruturas, como as Sinformas de Morro Grande, Colombo e Cachoeirinha estão relacionadas a falhas de retrocavalgamento e de cavalgamento, posicionando-se no flanco da Antiforma do Setuva.

E possível que as dobras do SDA resultem do esforço compressivo de segunda ordem, de direção NW-SE, relacionado à movimentação lateral-direita das principais transcorrências paranaenses, entre as quais estão as Falhas da Lancinha e de Morro Agudo. Entretanto, a Antiforma do Setuva não se enquadra nesse modelo, podendo duvidosamente estar relacionada à reativação lateral-esquerda da primeira.

Agradecimentos A realização deste trabalho só foi possível devido ao suporte financeiro oferecido pela FINEP/ PADCT, contrato ${ }^{\circ}$ 43.89.00.41.00 e à Mineropar-Mine- 
rais do Paraná S/A, através do Convênio UFPR/Mineropar. Agradecimentos especiais são devidos aos professores Elimar Trein e Paulo C. Soares pelas profícuas discussões sobre a geologia do Pré-Cambriano paranaense. Agradecimentos também ao desenhista Lepoldo C. Neto, pela elaboração das figuras apresentadas no texto.

\section{REFERÊNCIAS BIBLIOGRÁFICAS}

BIONDI, J.C. 1989. Mapa Geológico do Estado do Paraná. Escala 1:650.000. Curitiba, Mineropar.

BOYER, S.E. 1986. Styles of folding within thrust sheets: examples from the Appalachian and Rocky Mountains of the USA and Canadá. J. Struct. Geol., 8(6):325-339.

BOYER, S.E. \& ELLIOT, D. 1982. Thrust systems. Am. Assoc. Petrol. Geol. Bull. 66:1196-1230.

BUTLER, R.W.H. 1982. The terminology in thrust zones. /. Struct. Geol., 49(3):239-245

DIAS, M.V.F. \& SALAZAR, O., Jr. 1987. Geologia da Seqüência Antinha Grupo Açungui, Pr. In: SIMP. SUL-BRAS. GEOL., 3. Curitiba, 1987. Atas... Curitiba, SBG. p. 263-279.

EBERT H. 1971. Observações sobre a litologia e subdivisão do "Grupo Setuva" no Estado do Parana. In: CONGR. BRAS. GEOL., 25. São Paulo, 1971. Anais... São Paulo, SBG. v. 1, p. 131-165.

EVANS, A.M. 1963. Conical folding and oblique structures in Charnwood Forest, Leicesterchire. Proc. Yors. GeolSoc., 34:67-80.

FIORI, A.P. 1984. (coord.). Lineamentos Tectônicos e Possiveis Mineralizações Associadas no Pré-Cambriano Paranaense. Curitiba, Convênio UFPR/Mineropar. 2 v, 261 p. (Inédito).

FIORI, A. P. 1985. Avaliação preliminar do deslocamento dúctii das Falhas da Lancinha e de Morro Agudo no Estado do Paraná. BoL Paraná. Geociênc., 36:15-30.

FIORI, A.P.; FASSBINDER, E.; GOIS, J.R.; FUMAGALLI, C.E. 1987. Compartimentacão tectônica do Grupo Acungui a norte de Curitiba. In: SIMP. SUL-BRAS. GEOL., 3. Atas... Curitiba, SBG/NPR/NSC. p. 183-196.

FIORI, AP. 1991. Tectônica e Estratigrafia do Grupo Açungui a norte de Curitiba. São Paulo. 261 p. (Tese de Livre-Docência, IG-USP).

FIORI, A.P. 1992a. Tectônica e Estratigrafia do Grupo Açungui - Pr. Boi. IG-

USP, Ser. Cient., 23:55-74.

FIORI, A.P. 1992b. Considerações sobre a estratigrafia do Grupo Açungui PR. (no prelo).

FIORI, A.P. 1992c. O Sistema de Cavalgamento Açungui, PR. Geociências, (no prelo).

FRITZONS, O., Jr.; PERKARZ, G.F; FALCADE, D. 1982. Geologia e Pontencial Econômico do Grupo Setuva (PR). In: CONGR. BRÁS. GEOL., 32. Salvador, 1982. Anais... Salvador, SBG. v. 3, p. 987-1001.
HASUI, Y.; CARNEIRO, C.D.; COIMBRA, A.M. 1975. The Ribeira Folded Belt Rev. Bras. Geoc.. 4:257-266.

HASUI, Y.; EBERT, H.D.; QUADE, H. 1984. Aspectos geológicos da Megantiforma da Serra do Cadeado, Pr. In: CONGR. BRAS. GEOL., 33. Rio de Janeiro, 1984. Anais... Rio de Janeiro, SBG. v. 5, p. 2380-2393.

HENRY, M.J. 1976. Méthodes Modernes de Geologie de Terrain. Manuel $D$ 'Analise Struturale. 26 ed. Paris, Edition Technip. 72 p.

MARINI, O.J.; TREIN, E.; FUCK, R.A. 1967. O Grupo Açungui no Estado do Paraná. BoL Parana. Geociênc., 23/25:307-324.

MARINI, O.J. 1970. Geologia da Folha de Rio Branco do SuL Rio Claro. $190 \mathrm{p}$. (Tese de Doutoramento, FFCLRC-UNESP).

PIERKARZ, G.F. 1984. Geologia e resultados preliminares da pesquisa no Núcleo Betara da Formação Perau (PR). In: CONGR. BRAS. GEOL, 33. Rio de Janeiro, 1984. Anais... Rio de Janeiro, SBG. v. 7, p. 36823696.

PONTES, J.B. 1982. Geologia e potencialidades econômicas da Formação Água Clara (PR).In: CONOR. BRAS. GEOL, 32. Salvador, 1982. Anais... Salvador, SBG, v. 3, p. 1002-1016.

RAMSAY, J.G. \& HUBER, M.I. 1983. The Techniques of Modem Structural Geology. Strain Analysis. London, Academic Press, v. 1, $307 \mathrm{p}$.

SCROLL W. V. 1981. Geologia do Grupo Açungui na região a noroeste de Rio Branco do Sul, Paraná. In: SIMP. REG. GEOL, 3. Atas... Curitiba, SBG. V. 1 p. $170-184$.

SOARES, PC. \& GOIS, J.R. 1987. Geologia do Granito Passa Três (Paraná) e suas mineralizacões auríferas. In: SIMP. SUL-BRAS. GEOL, 3. Alas... Curitiba, SBG/NPR/NSC/NRS. v. 2 p. 497-514.

WILCOX, R.E.; HARDING, T.P.; SEELY, D.R. 1973. Basic wrench tectonics. Am. Ass. Petrol. Geol. Bull., 57:74-96.
MANUSCRITO A749

Recebido em 21 de outubro de 1992 Revisfto do autor em 26 de abril de 1993 Revisão aceita em 5 de maio de 1993 